\title{
Specialty choices of postgraduate medical students: Are they related to the kind of animal identified with oneself?
}

\author{
Raman Deep Pattanayak ${ }^{1}$, Manju Mehta ${ }^{2}$, Rajesh Sagar ${ }^{3}$
}

\begin{abstract}
Background: Research has pointed to a possible role of certain personality attributes in the choice of medical specialties, but not much is known about the Indian setting. Furthermore, most personality assessments are quite lengthy and time-consuming.

Objective: The study aimed to explore if the specialty choices of Indian postgraduate students are related to their personality attributes, using a brief projective animal question.

Methods: The study was carried out as a retrospective survey $(n=450)$ of responses to a projective question, in which students were asked to name the animal they identified themselves with the most and their reasons.

Results: Mean age was $25.46 \pm 1.94$ years (Males: $71.8 \%$ males; females: $28.2 \%$ ). Reasons for identification with the stated animal were categorized as aggressive $11.8 \%$, autonomous $40 \%$, nurturing $30.4 \%$ and aesthetic $17.8 \%$. Technology-oriented specialties were associated with aggressive/ autonomous responses $(p<0.01)$, while pre/paraclinical specialties were associated with nurturing/aesthetic responses $(p<0.01)$. Females had twice the odds (OR: 1.86) of choosing a personoriented clinical specialty over a technology-oriented specialty.
\end{abstract}

Conclusion: Research in this direction is needed to assist the career counseling of medical students.

Keywords: medical students, specialty choice, gender, personality, India

\section{Introduction}

The choice of a specialty is an important decision in the career of a medical student and vocational interests are, often, an expression of one's own personality. Research has pointed to a possible association of personality attributes with medical specialty choices (Borges et al, 2002).

\footnotetext{
${ }^{1}$.Senior Research Associate (CSIR), Department of Psychiatry

2. Professor of Clinical Psychology, Department of Psychiatry

${ }^{3}$.Additional Professor, Department of Psychiatry

All India Institute of Medical Sciences

Ansari Nagar, New Delhi, India-110029

Correspondence author:

Dr Manju Mehta, Professor of clinical psychology

Department of Psychiatry

All India Institute of Medical Sciences

Ansari Nagar, New Delhi, India-110029

Tel: 011-26594412; 26588500 (4412 extn)
}

The study aimed to explore if the specialty choices of Indian postgraduate students are related to their personality attributes, using a brief projective animal question.

\section{Method}

The study was conducted at a tertiary care hospital in India, with an annual capacity of over 400 postgraduate seats. At the time of admission, students are administered a brief projective question for animal self-identification (details below) as part of the questionnaire for a psychological assessment. Students are encouraged to be open, honest and spontaneous in their responses. The responses of students do not bear any consequences to their admission.

The study was carried out in a retrospective manner, with retrieval of the information pertaining to gender, name of the specialty and projective test responses of 450 postgraduate students. Complete anonymity has been ensured in presentation of results. No identifying information has been included. 
Projective question for animal self-identification

It is a two-part question in which students are asked to (a) name the animal with which they can identify themselves with the most and, (b) to state the reason for doing so. The responses were categorized by researchers into four broad categories (Kaplan et. al., 1967; Farrell et. al., 1975) based on the reasons for identification.

(a) Aggressive: because it attacks, bites, scratches, fights, or is fierce, combative, hostile, and unfriendly;

(b) Autonomous: because of its freedom, independence large size, muscular vigor, physical efficacy, self-reliance or decisiveness;

(c) Nurturing: because it provides or craves for shelter, protection, love, well-being, food, and/or support;

(d) Aesthetic: because it is beautiful, delicate, graceful, aesthetically pleasing, or leads a calm or good life.

To give an example, if a student identifies with a dog because it can bite others, or induce fear in others, it is an aggressive response, but if a dog is chosen because of its affection and loyal attitude, then it is a nurturing response.

\section{Statistical analysis}

The descriptive statistics was used for sample characteristics. Chi-square test and multinomial logistic regression were conducted using Statistical Package for Social Sciences.

\section{Results}

\section{Sample characteristics}

The mean age of students was $25.46 \pm 1.94$ years. There were $71.8 \%$ male and $28.2 \%$ female students. The specialties and their frequency distribution were as follows:

(a) Person-oriented clinical specialties (medicine, pediatrics, gynecology \& obstetrics, dermatology, community medicine, physical med \& rehabilitation and psychiatry): $32.9 \%, \mathrm{n}=148$.

(b) Technology-oriented clinical specialties (anesthesiology, surgery, ophthalmology, otolaryngology, orthopedics, radiology, radiotherapy and nuclear medicine): $42 \%$, $\mathrm{n}=189$.

(c) Pre/paraclinical specialties (anatomy, physiology, biochemistry, pharmacology, microbiology, pathology, laboratory medicine, forensic medicine and biophysics): $25.1 \%, \mathrm{n}=113$.
The person and technique-oriented taxonomy used has been employed in previous literature (Zeldow et.al., 1990, Borges et. al., 2005). It is based on functions performed on a day to day basis, for example, working with people or performing techniques/procedures on people or a non-clinical work.

\section{Projective animal responses}

The projective test generated 52 types of responses, ranging from domestic (cat, cow) to wild (lion, bear), large-sized (elephant, whale) to small (ant), quick (rabbit, tiger) to slow and calm (tortoise), general categories (dog, fish) to precise breed (Labrador, dolphin), common (monkey) to uncommon (ostrich) and some even mythological (unicorn, phoenix) animals.

The aggressive responses were $11.8 \%$, autonomous $40 \%$, nurturing $30.4 \%$ and aesthetic $17.8 \%$. Some of the interesting responses have been provided below:

Dog: loves people unconditionally like me, faithful

Peacock: good dancer like me; elegant and graceful

Lion: I am a king like him; fierce and powerful 'never give up' attitude

Eagle: independent, no group-hunting

Cow: helpful to others, gives milk to humans

Specialty choices: Relation to projective animal responses

Students with autonomous/ aggressive responses were significantly over-represented $(59.3 \%)$ in the technology-oriented specialties, while those with nurturing/ aesthetic responses were significantly over-represented $(59.8 \%)$ in the person-oriented specialties. The findings of chi-square test are shown in table 1.

The logistic regression generated a significant model $(\chi(4)=20.45, p<0.01)$. Gender and projective animal traits emerged as the significant predictors for type of medical specialty. Female students had twice the odds (OR: 1.86) of choosing a person-oriented specialty over a technology-oriented specialty. The students with nurturing/aesthetic responses had twice the odds (OR: 2.22) of choosing a pre/paraclinical specialty over a technologyoriented specialty. 
Table 1: Specialty types: Relation to projective animal traits $(N=450)$

\begin{tabular}{lcccc}
\hline & $\begin{array}{c}\text { Aggressive or } \\
\text { autonomous }\end{array}$ & $\begin{array}{c}\text { Nurturing or } \\
\text { aesthetic }\end{array}$ & $\begin{array}{c}\text { Chi-square } \\
\text { Test }\end{array}$ & $\begin{array}{c}\text { Adj. residual } \\
(\mathrm{R})\end{array}$ \\
\hline Specialty choice & $72(51.4 \%)$ & $76(48.6 \%)$ & $\gamma=10.94$ & 0.8 \\
Person-oriented & $113(59.3 \%)$ & $76(40.7 \%)$ & $\mathrm{df}=2$ & $2.6^{*}$ \\
Technology-oriented & $46(40.2 \%)$ & $67(59.8 \%)$ & $\mathrm{p}=0.004^{*}$ & $3.1^{*}$ \\
Pre/paraclinical & & & & \\
\hline
\end{tabular}

Statistical analysis by Chi-square test; Adjusted residual $\geq 2$ is considered significant to indicate groups which are significantly different on chi-square test

\section{Discussion}

The technology-oriented specialties had a higher representation of aggressive/ autonomous responses, in consonance with previous literature (Borges et. al., 2002; Borges et. al., 2005). Studies suggest that physicians in a technology-oriented specialty like surgery or anesthesiology are more achievementoriented and extroverted than the family practitioners, while residents in family practice and internal medicine score higher on humanistic attitudes.

Another main finding was that the nurturing / aesthetic responses were highly predictive of a pre/Para clinical specialty (OR: 2.22) over a technology-oriented specialty. The pre/Para clinical specialties are associated with predefined working hours and a more relaxed lifestyle, which may be more conducive to nurturing or aesthetic attributes. The kind of work involved in certain pre/preclinical specialties may be perceived as more aesthetic than a technology-driven clinical specialty.

The female gender was significantly predictive of choosing a person-oriented specialty (OR:1.39) compared to a technology-oriented specialty, which could possibly be explained by a higher capability to relate with people, a higher focus on emotion or gender specific role and expectations.

The study has several limitations. The projective question should be treated more as a preliminary exploration, and to be built upon its reliability and other properties. It is a brief and easy-to-use tool, but does not provide assessment on multiple dimensions like a comprehensive battery. The study did not focus on other factors e.g. socioeconomic status which may influence specialty choice.

The pattern of specialty choices governs the future health care system of a nation and merits a closer attention. Research in this direction may help in career counseling for the medical students and assist in matching the personality to specialty types.

\section{References}

Borges, N.J. \& Gibson, D.D. Personality patterns of physicians in person-oriented and techniqueoriented specialties, Journal of Vocational Behavior, 2005, 67, pp. 4-20.

Borges, N.J. \& Savickas, M.L. Personality and Medical Specialty Choice: A Literature Review, Journal of Career Assessment, 2002, 10, pp. 362.

Farrell, M.F. \& Gumley, D. The "Animals Questions" technique: A short projective instrument, British Journal of Projective Psychology \& Personality Study, 1975, 20, pp. 31-2.

Kaplan, H.K. \& Calden, G. An Elaboration of the "Projective Question" the Animal Test, Journal of Clinical Psychology, 1967, 23, pp. 204.

Zeldow, P.B., Devens, M. \& Daugherty, S.R. Do person-oriented medical students choose person-oriented specialties? Do technologyoriented medical students avoid personoriented specialties?, Acad. Med., 1990, 65, pp. S45-6. 